\title{
GALILEO'S PENDULUM AS A MAGNETIC BALANCE FOR STUDYING CHEMICAL MAGNETISM AT HOME
}

\author{
Henrique E. Toma ${ }^{\mathrm{a}, *,(1)}$ \\ anstituto de Química, Universidade de São Paulo, 05508-000São Paulo - SP, Brasil
}

Recebido em 17/06/2020; aceito em 16/07/2020; publicado na web em 04/09/2020

\begin{abstract}
A very simple, but rich experiment, encompassing a classical Galileo's pendulum, has been devised to be performed at home, especially during the Covid-19 pandemics. The experiment uses a miniature supermagnet rod as the pendulum oscillating element suspended from a fixed sewing thread. Its physics can be fully investigated, allowing to study the oscillation movements and to extract the gravity acceleration constant. The interaction with chemical substances can be accurately monitored by equilibrating the magnetic attraction of the probe as it opposes the gravity restoring force. Magnetic susceptibilities can be precisely measured in this way, allowing to access the number of unpaired electrons in the compounds, while stimulating discussions in the light of the ligand field theory. The simplicity and the opportunity of joining physics and chemistry are the most relevant aspects of the experiment. Curiously, the pendulum performance also implies a meditation like posture, requiring complete silence and confinement. In this sense it can also help relaxing our mind during the pandemics.
\end{abstract}

Keywords: Galileo's pendulum; magnetic balance; magnetic susceptibility; pendulum physics; paramagnetism.

\section{INTRODUCTION}

Covid-19 pandemics is challenging the teaching of experimental sciences, demanding new didactic approaches for home and long distance learning. Experiments should be reinvented for achieving this goal and for enhancing science education skills. A suggestive approach be implemented during this crisis are the science kits, as exemplified by the project "Adventures in the Science" conducted by professors Nussenzweig, Toma, Zats, Colli, Dessen, Bagnato and Barbui, in Brazil. ${ }^{1}$

Along this line, this work introduces another interesting experimental approach which can be readily applied for teaching chemical magnetism and Galileo's pendulum physics ${ }^{2}$ at home. The paper actually describes a simple way of determining magnetic susceptibilities of inorganic compounds, encompassing experiments which can be easily performed, combining relevant physical and chemical concepts.

Magnetism is a fundamental property of matter and its understanding is essential for dealing with many natural phenomena and current technologies. It was elegantly explored by Michael Faraday about 200 years ago, and explained by Joseph van Vleck in the last century in terms of the electron spin distribution in the atoms. ${ }^{3}$ Its relevance in chemistry and nanotechnology has increased dramatically in the last years, and many applications have been devised in medicine, particularly in theranostics and NMR imaging. ${ }^{4,5}$ However, in spite of this, magnetism is seldomly explored in chemistry undergraduate courses, in part because magnetic measurements require expensive equipment, not accessible in most teaching laboratories. An alternative, low cost approach has already been proposed by using external weighing devices adapted to conventional analytical balances, for measuring the influence of the magnetic field on the samples. ${ }^{6-8}$ This task has become feasible thanks to the availability of miniature supermagnets in the market, based on $\mathrm{Nd}_{2} \mathrm{Fe}_{14} \mathrm{~B}$ alloys, which afford very strong magnetic fields $(11 \mathrm{kOe}) .{ }^{9}$ Unfortunately, such external weighing devices cannot be applied at home, by the lack of analytical balances. So, another strategy is required, and here it is explored a classical

*e-mail: henetoma@iq.usp.br
"Galileo's pendulum", ${ }^{10}$ encompassing a miniature supermagnet as the oscillating body.

Pendulums can be found everywhere and have many uses, particularly in ornamental clocks or just for fun. They have been very important in history, since the classical Galileo study, ${ }^{10}$ in 1583, of the chandelier movements in the Pisa Church (Figure 1A). Nowadays, it is extensively used for teaching oscillation mechanics and gravitation. ${ }^{2}$ The simplest pendulum design is composed by a body suspended from a fixed support. The body can swing freely back and forth, under a conservative regime dictated by the gravity. When the body is displaced sideways from its resting equilibrium position, a tangential restoring force arises accelerating it back toward the equilibrium position. However, the interconversion between the kinetic and potential energies makes it swinging back and forth indefinitely, allowing the pendulum to be used as a clock. Although the mathematic equations involved can be very complicated, for small-angle displacements the pendulum theory
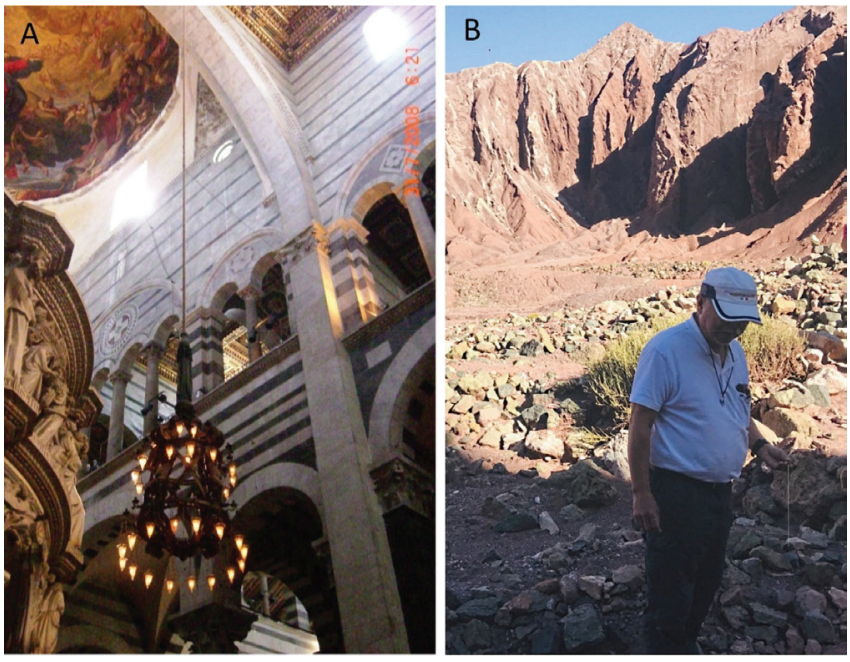

Figure 1. (A) Galileo's theory was inspired from this chandelier movements, in 1583, at the cathedral of Pisa (B) the pendulum balance was inspired from an excursion to the Atacama desert, looking for meteorites with a magnetic probe (credit: H. E. Toma) 
approaches a simple harmonic oscillator and the exact solutions are quite simple.

The idea of combining pendulum oscillations and chemical magnetism was conceived during an excursion to the Atacama desert, in Chile. Atacama is one of the preferred places for excursionists interested in meteorites and there is a remarkable museum and research center located there. ${ }^{11}$ In our journey to the desert, a miniature supermagnet suspended by a sewing thread was employed as a prospecting pendulum probe (Figure 1B). At the proximity of magnetic rocks the oscillation of the pendulum changes dramatically while moving in the direction of the mineral target. Surprisingly, such simple strategy did work well and was very fun! Now, the same pendulum approach is being explored for studying the magnetic properties of inorganic compounds.

The use of the pendulum as a magnetic balance requires the understanding of the physics of the pendulum and the nature of the magnetism in chemical compounds. The experimental setup uses just a small magnet suspended by a sewing thread. The pendulum can be easily assembled as indicated in Figure 2, using a door frame to support the magnet. The chemical compounds of interest should be supplied by the professor. Although the experiment is rather simple, it is very rich and provides a unique opportunity for teaching physical and chemical concepts at home.

\section{Experimental section}

The magnetic measurements were carried out with a miniature magnet rod, e.g. $10 \mathrm{~mm}$ length and $5 \mathrm{~mm}$ diameter, composed by a $\mathrm{Nd}_{2} \mathrm{Fe}_{14} \mathrm{~B}$ alloy $(11.0 \mathrm{kOe})$, available in the market by less than $\mathrm{U} \$ 25$ cents. ${ }^{9}$ The pendulum is composed by the magnet rod suspended from a convenient support, such as a door frame, using a sewing thread tied to a small adhesive tape, as shown in Figure 2. The magnet should be accommodated at the horizontal position. With the pendulum mounted, a graph millimetric paper should be placed below the magnet rod, keeping a distance of about 5 to $10 \mathrm{~mm}$ from the ground. The suspended magnet performs exactly like a compass; its spontaneous orientation defines the SN magnetic axis which should be indicated in the graph paper by a straight line. The $\mathrm{SN}$ axis provides a guide line for approaching the sample close to the magnet. But the critical point for the success of the experiment is the choice of the place and time for performing the experiment. The pendulum is extremely sensitive to any air current and trepidation. It responds to less than 0.2 $\mathrm{mm}$ perturbations from the sample. For this reason, the performance involves a meditation like posture, requiring complete silence and confinement. Iron and nickel objects should also be removed from the proximity, but their presence is readily signaled by the magnetic probe, which acts as a compass. The best choice is to have the door closed, using a chopstick fixed at the top frame with an adhesive tape, in order to work as a cantilever. The sewing thread should be long enough to be fixed also at the lateral frame, as in Figure 2.

The sample should be finely grinded and placed into a cylindrical screw cap tube, up to $10 \mathrm{~mm}$ height or more. It should be compacted by knocking on the table, or preferentially by pressing inside the tube with small piston (e. g. from a $1 \mathrm{~mL}$ syringe). The tube should be positioned on the magnetic line of the graph paper and carefully moved towards the magnet in order to make contact. At the interacting distance, the pending magnet is readily attracted by the paramagnetic sample. It is recommended to keep the system in this form for a few minutes, to stabilize the probe. After this, the sample should be displaced carefully along the axis. The magnet will remain attached to the sample up to a limiting distance where the pendulum restoring force exceeds the magnetic attraction. This detachment point can be precisely measured on the graph paper. The measurements should be repeated many times for improving accuracy. Since the pendulum response is extremely sensitive, one can use a smartphone for imaging and amplifying the reading, providing precise values of the oscillation distance with at least $\pm 0.2 \mathrm{~mm}$ accuracy.

\section{RESULTS AND DISCUSSION}

\section{Measurement of the restoring force and magnetism}

According to the pendulum scheme (Figure 3) the interaction between the magnet and the sample leads to the attraction of the pendulum body. When the sample is moved back along the magnetic axis a rupture point is reached, corresponding to the distance $\mathrm{d}$, where the attracting magnetic force $\mathrm{F}_{2}$ equilibrates the pendulum restoring force $F_{1}$; i. e. $F_{1}=F_{2}$.

$\mathrm{F}_{1}$ is given by

$$
\mathrm{F}_{1}=\mathrm{m} \cdot \mathrm{g} \cdot \operatorname{sen} \theta
$$

where $\mathrm{m}$ is the mass of the magnet (e. g. $1.6338 \mathrm{~g}$ ) and $\mathrm{g}$ is the gravity constant. For small $\theta, \operatorname{sen} \theta \approx d / L$

$\mathrm{F}_{2}$ corresponds to the force induced by the magnetic fied:

$$
F_{2}=\mu_{o} H\left(\frac{\partial H}{\partial x}\right)
$$

where $\chi$ is the magnetic susceptibility of the sample, $\mu_{\mathrm{o}}$ is the Bohr magneton $(\mathrm{BM})$ constant $\left(\mathrm{eh} / 4 \pi \mathrm{m}=0.927 \times 10^{-20} \mathrm{erg} / \mathrm{Gauss}\right)$, and $\mathrm{H}$ is the applied magnetic field.

Although it is possible to calculate $F_{1}$ using the values of $\mathrm{m}, \mathrm{g}$ and the $d / L=\operatorname{sen} \theta$, it is more convenient to use an empirical procedure

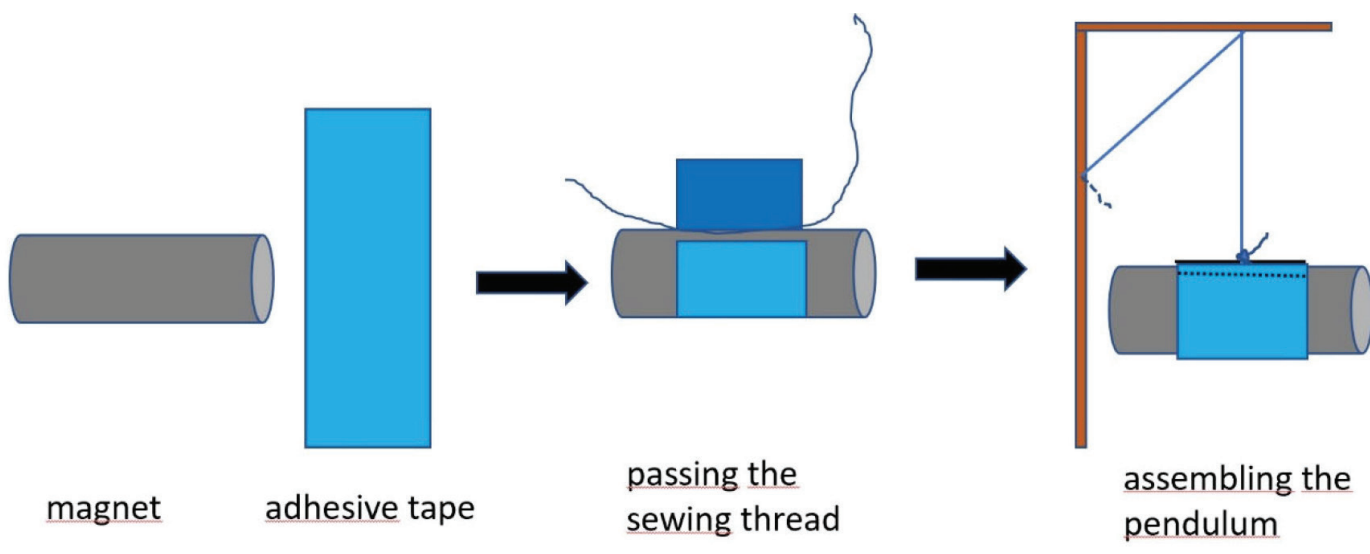

Figure 2. Sequential steps for assembling the magnetic probe at the pendulum 


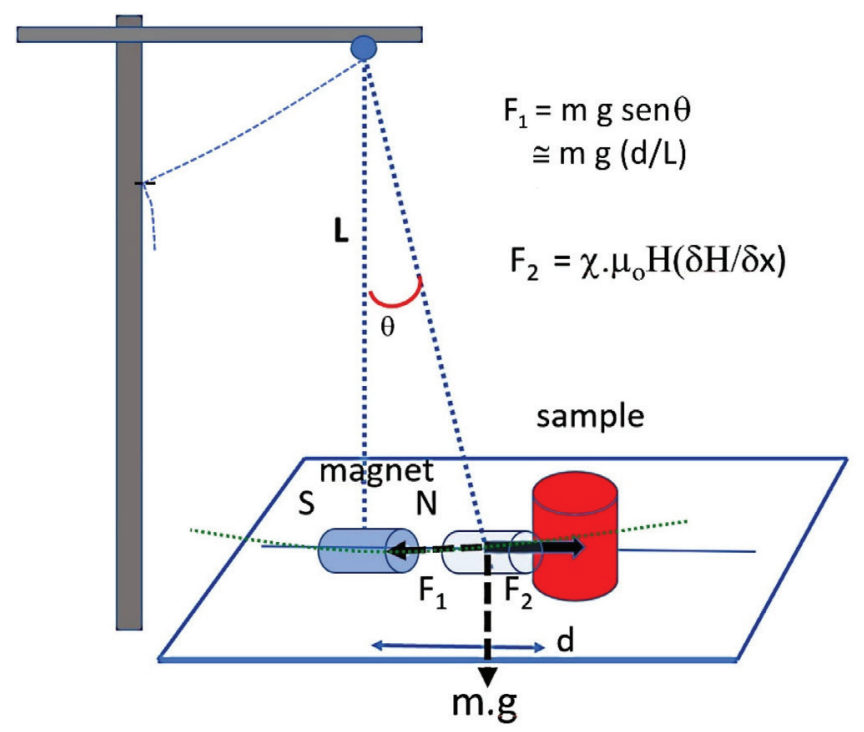

Figure 3. Pendulum movement showing the restoring force $\left(F_{1}\right)$ and magnetic attraction to the sample $\left(F_{2}\right)$

usually applied to determine the magnetic susceptibility constant $\chi$, by calibrating the experiment with a standard sample such as $\mathrm{FeSO}_{4} \cdot 7 \mathrm{H}_{2} \mathrm{O}\left(\chi=11.2 \times 10^{-3} \mathrm{~cm}^{3} \mathrm{~mol}^{-1}\right){ }^{12}$ This procedure allows to cancel the influence of any possible variables, such as air resistance and magnetic fluctuations from the environment.

For obtaining the magnetic constants, equations (1) and (2) should be compared and transformed into (3) and (4).

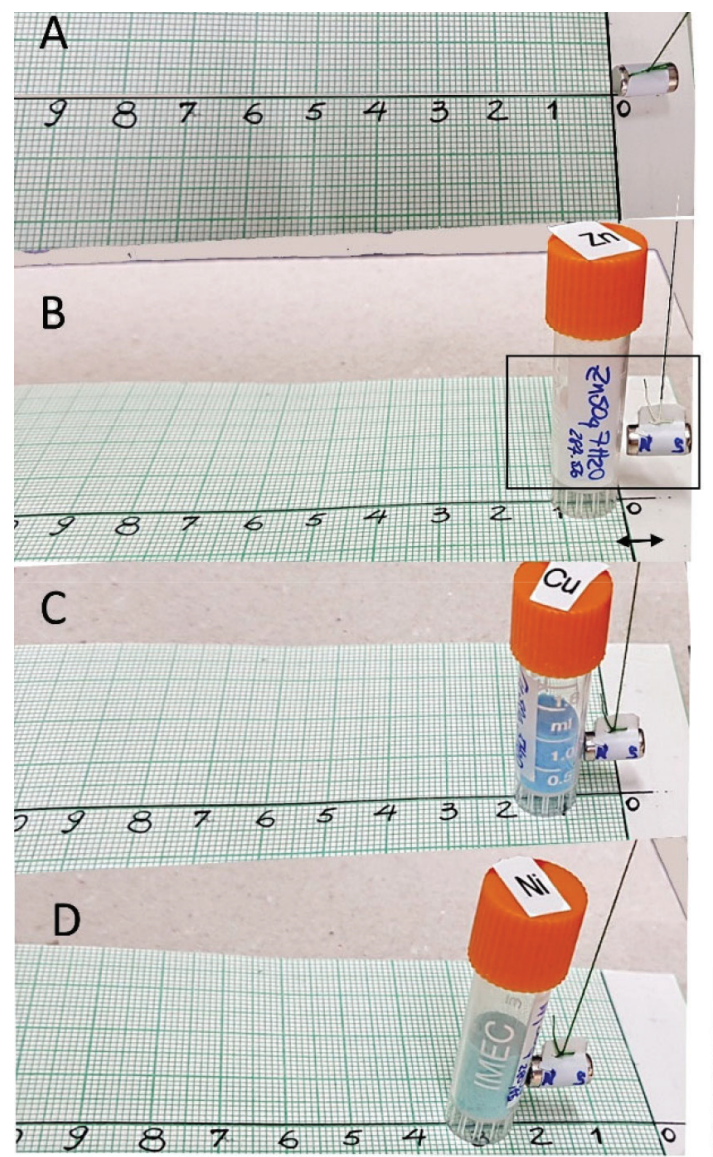

$$
\begin{aligned}
& \mathrm{F}_{\text {sample }}=\mathrm{m}_{\text {magnet. }} \mathrm{g} \cdot \frac{\mathrm{d}_{\text {sample }}}{\mathrm{L}}=\chi_{\text {sample }} \cdot \mu_{\mathrm{o}} \mathrm{H}\left(\frac{\partial \mathrm{H}}{\partial \mathrm{x}}\right) \\
& \mathrm{F}_{\text {standard }}=\mathrm{m}_{\text {magnet. }} \mathrm{g} \cdot \frac{\mathrm{d}_{\text {standard }}}{\mathrm{L}}=\chi_{\text {standard }} \cdot \mu_{\mathrm{o}} \mathrm{H}\left(\frac{\partial \mathrm{H}}{\partial \mathrm{x}}\right)
\end{aligned}
$$

Dividing the two equations, the following relationship is obtained:

$$
\frac{\mathrm{d}_{\text {sample }}}{\mathrm{d}_{\text {standard }}}=\frac{\chi_{\text {sample }}}{\chi_{\text {standard }}}
$$

and

$$
\chi_{\text {sample }}=\chi_{\text {standard }}\left(\frac{\mathrm{d}_{\text {sample }}}{\mathrm{d}_{\text {standard }}}\right)
$$

So, in order to obtain the magnetic susceptibility of a sample, the distance $\mathrm{d}$, corresponding to the detachment point, should be first determined for a standard compound, and then the measurement should be repeated with the sample, by keeping the same experimental arrangement. In this experiment, the $\mathrm{FeSO}_{4} 7 \mathrm{H}_{2} \mathrm{O}$ compound was taken as reference because of its chemical purity, good thermal and mechanical stability, low cost and for exhibiting intermediate magnetization parameters for allowing more accurate measurements of conventional samples. By using this standard, all the magnetic susceptibilities are expressed in $\mathrm{cm}^{3} \mathrm{~mol}^{-1}$ and there is no need to correct for the molecular mass of the compounds.

The typical performance of the pendulum balance is shown in Figure 4, and Table 1. All the measurements were carried out in triplicate.

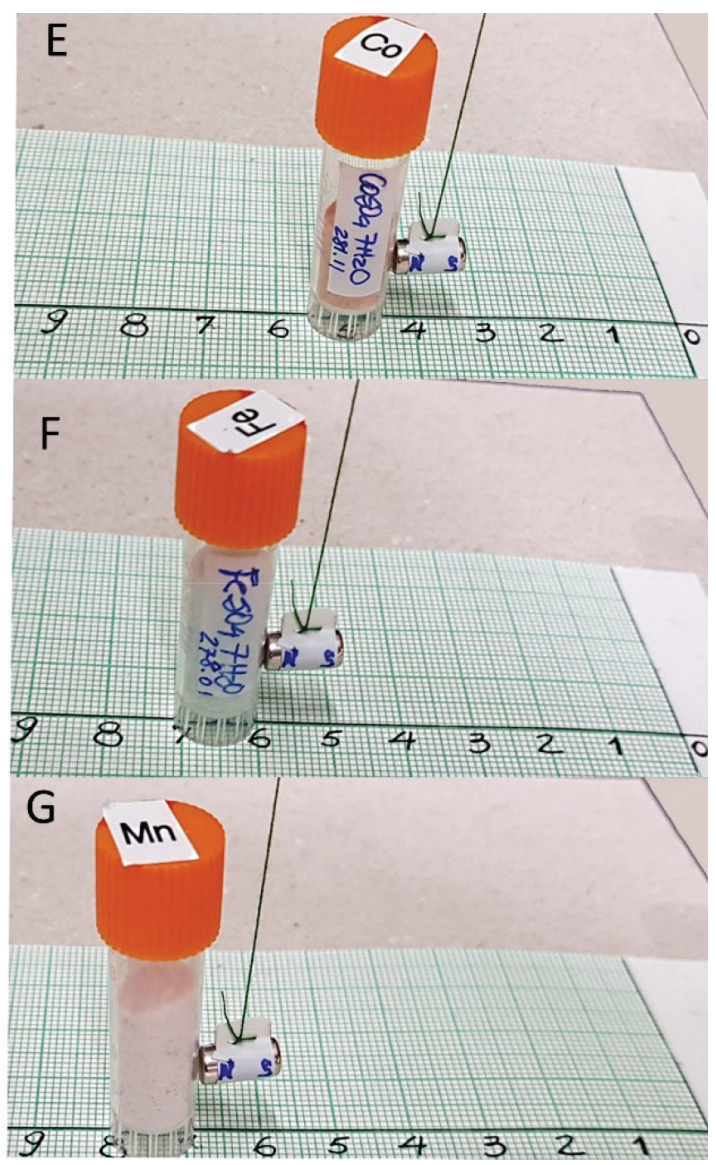

Figure 4. Typical measurements showing (A) the starting point with the magnet aligned with the magnetic axis, and typical rupture distances at the critical point for $(\mathrm{B}) \mathrm{ZnSO}_{4} \cdot 7 \mathrm{H}_{2} \mathrm{O}$ (diamagnetic repulsion can be seen in the frame), (C) $\mathrm{CuSO}_{4} \cdot 5 \mathrm{H}_{2} \mathrm{O}$, (D) $\left.\left.\mathrm{NiSO}_{4} \cdot 7 \mathrm{H}_{2} \mathrm{O}, \mathrm{E}\right) \mathrm{CoSO}_{4} \cdot 7 \mathrm{H}_{2} \mathrm{O}, \mathrm{F}\right) \mathrm{FeSO}_{4} \cdot 7 \mathrm{H}_{2} \mathrm{O}$ and $(\mathrm{G})\left[\mathrm{Mn}(\mathrm{Ac})_{2}\left(\mathrm{H}_{2} \mathrm{O}\right)_{4}\right.$ 
As shown in Table 1, the restoring distances are dependent upon the pendulum height $(\mathrm{L})$, while the associated magnetic forces increase with the number of unpaired electrons from $\mathrm{Cu}^{\mathrm{II}}\left(\mathrm{d}^{9}\right)$ to $\mathrm{Mn}^{\mathrm{II}}\left(\mathrm{d}^{5}\right)$. In the case $\mathrm{ZnSO}_{4} \cdot 7 \mathrm{H}_{2} \mathrm{O}$, there is a visible repulsion between the magnet and the sample, reflecting its diamagnetic nature.

The diamagnetic contribution of the ligands and anions can be calculated using the Pascal constants, ${ }^{13,14}$ in order to evaluate the magnetic susceptibility of the metal ion alone, $\chi_{\text {metal }}$ :

$\chi_{\text {metal }}=\chi_{\text {compound (negative value) }}+\Sigma \chi_{\text {diamagnetic contributions (positive values) }}$

The calculated contribution of the diamagnetic constants can be seen in Table 1 and are practically negligible, except for the $\mathrm{CuSO}_{4} .5 \mathrm{H}_{2} \mathrm{O}$ compound which exhibits only one unpaired electron. The results for the $\mathrm{ZnSO}_{4} \cdot 7 \mathrm{H}_{2} \mathrm{O}$ sample are quite consistent with the diamagnetism of the compound (Table 1).

The effective moment $\left(\mu_{\mathrm{ef}}\right)$ is related with the magnetic susceptibility $\chi$ according to the Curie equation ${ }^{13,15}$

$$
\chi=\frac{N_{A}^{2} \mu^{2}}{3 k T}
$$

where $\mathrm{N}_{\mathrm{A}}$ is the Avogadro number, $\mathrm{k}$ is the Boltzmann constant and $\mathrm{T}$ is the Kelvin temperature.

The magnetic moments can be calculated by rearranging equation (8) as

$$
\mu_{\mathrm{ef}}=\sqrt{\frac{3 k \chi T}{N_{A}^{2}}}=2.828 \sqrt{\chi T}
$$

\begin{tabular}{|c|c|c|c|c|c|}
\hline Compound and properties & $\begin{array}{c}\mathrm{L} / \mathrm{cm} \\
( \pm 1) \\
\end{array}$ & $\begin{array}{c}\mathrm{d} / \mathrm{cm} \\
( \pm 0.02)\end{array}$ & $\chi_{\text {molar } / 10}{ }^{-3} / \mathrm{cm}^{3} \mathrm{~mol}^{-1}$ & $\mu_{\mathrm{ef}} / \mathrm{BM}$ & $\mathrm{n}$ \\
\hline $\begin{array}{l}{\left[\mathrm{MnAc}_{2}\left(\mathrm{H}_{2} \mathrm{O}\right)_{4}\right]^{*}} \\
3 \mathrm{~d}^{5}(5 \text { unpaired e }) \\
\mathrm{MM}^{-} 169.00 \mathrm{~g} \mathrm{~mol}^{-1} \\
\Sigma \chi_{\text {diamag }} / 10^{-3} \\
\mathrm{~cm}^{3} \text { mol }^{-1} \\
\text { Average } \chi_{\text {molar }}\end{array}$ & $\begin{array}{l}75 \\
100 \\
125 \\
150 \\
200\end{array}$ & $\begin{array}{l}2.60 \\
4.00 \\
5.10 \\
6.90 \\
9.40\end{array}$ & $\begin{array}{l}13.3 \\
12.8 \\
12.7 \\
12.9 \\
12.7 \\
12.9\end{array}$ & 5.54 & 4.7 \\
\hline 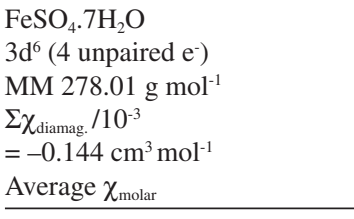 & $\begin{array}{c}75 \\
100 \\
125 \\
150 \\
200\end{array}$ & $\begin{array}{l}2.18 \\
3.52 \\
4.48 \\
6.00 \\
8.30\end{array}$ & $\begin{array}{l}11.2 \\
11.2 \\
11.2 \\
11.2 \\
11.2\end{array}$ & 5.16 & 4.2 \\
\hline 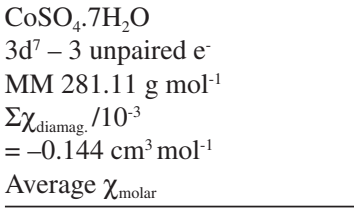 & $\begin{array}{c}75 \\
100 \\
125 \\
150 \\
200\end{array}$ & $\begin{array}{l}1.60 \\
2.30 \\
3.15 \\
4.50 \\
5.40\end{array}$ & $\begin{array}{l}8.2 \\
7.3 \\
7.8 \\
8.4 \\
7.3 \\
7.8 \\
\end{array}$ & 4.31 & 3.4 \\
\hline $\begin{array}{l}\mathrm{NiSO}_{4} .7 \mathrm{H}_{2} \mathrm{O} \\
3 \mathrm{~d}^{8}-2 \text { unpaired e} \\
\mathrm{MM}_{2} 280.86 \mathrm{~g} \mathrm{~mol}^{-1} \\
\Sigma \chi_{\text {diamag. }} / 10^{-3} \\
=-0.144 \mathrm{~cm}^{3} \mathrm{~mol}^{-1} \\
\text { Average } \chi_{\text {molar }}\end{array}$ & $\begin{array}{c}75 \\
100 \\
125 \\
150 \\
200\end{array}$ & $\begin{array}{l}0.90 \\
1.25 \\
1.76 \\
2.40 \\
3.20\end{array}$ & $\begin{array}{l}4.6 \\
4.0 \\
4.4 \\
4.5 \\
4.3 \\
4.3 \\
\end{array}$ & 3.20 & 2.3 \\
\hline $\begin{array}{l}\mathrm{CuSO}_{4} .5 \mathrm{H}_{2} \mathrm{O} \\
3 \mathrm{~d}^{9}-1 \text { unpaired e} \\
\mathrm{MM}^{-} 249.68 \mathrm{~g} \mathrm{~mol}^{-1} \\
\Sigma \chi_{\text {diamag. }} / 10^{-3} \\
=-0.118 \mathrm{~cm}^{3} \mathrm{~mol}^{-1} \\
\text { Average } \chi_{\text {molar }}\end{array}$ & $\begin{array}{c}75 \\
100 \\
125 \\
150 \\
200\end{array}$ & $\begin{array}{l}0.30 \\
0.45 \\
0.60 \\
0.75 \\
1.05\end{array}$ & $\begin{array}{l}1.5 \\
1.4 \\
1.5 \\
1.4 \\
1.3 \\
1.4\end{array}$ & 1.82 & 1.0 \\
\hline 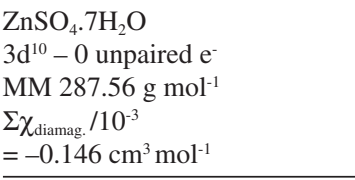 & $\begin{array}{c}75 \\
100 \\
125 \\
150 \\
200\end{array}$ & $\begin{array}{l}-0.10 \\
-0.12 \\
-0.15 \\
-0.15 \\
-0.20 \\
\end{array}$ & & & \\
\hline Free period of oscillation / s & $\begin{array}{l}75 \\
100 \\
125 \\
150 \\
200\end{array}$ & $\begin{array}{l}1.76 \\
2.00 \\
2.22 \\
2.30 \\
2.81\end{array}$ & & & \\
\hline $\begin{array}{l}\text { Calculated gravity constant, } \mathrm{g} \text {, } \\
\left(\mathrm{m} \mathrm{s}^{-2}\right) \\
\text { Average }=9.81 \mathrm{~m} \mathrm{~s}^{-2}\end{array}$ & $\begin{array}{c}75 \\
100 \\
125 \\
150 \\
200\end{array}$ & $\begin{array}{l}9.54 \\
9.85 \\
10.0 \\
9.72 \\
9.98\end{array}$ & & & \\
\hline
\end{tabular}

Table 1. Magnetic susceptibilities obtained from the pendulum balance for a series of transition metal hydrated salts

$* \mathrm{Ac}=$ acetate ion, $\mathrm{CH}_{3} \mathrm{CO}_{2}^{-}, 298 \mathrm{~K}$. 
Although the magnetic moment is theoretically given by the van Vleck equation

$$
\mu_{\mathrm{J}}=\mathrm{g}_{\mathrm{J}} \sqrt{J(J+1)}
$$

where $g_{\mathrm{J}}$ is the Landé's factor,

$$
\mathrm{g}_{\mathrm{J}}=\frac{1+[S(S+1)-L(L+1)+J(J+1)}{2 J(J+1)}
$$

for light transition metal elements, the contribution of spin-orbit coupling is almost negligible, and the $\mathrm{L}$ e and $\mathrm{J}$ terms can be abandoned. In this way, the situation will be described by the "spinonly" approximation, where the magnetic moment can be expressed in terms of the number of unpaired electrons, $n$ :

$$
\mu_{\mathrm{ef}}=\sqrt{n(n+2)}
$$

This calculation allows to estimate the number of unpaired electrons from the determination of magnetic susceptibility of $3 \mathrm{~d}$ elements as shown in Table 1. These results are in good agreement with the literature, although they seem only approximate because of the complete neglect of the spin-orbit interaction in the formalism. ${ }^{13,14}$ The influence of the pendulum length, $\mathrm{L}$ on the measurements is also quite relevant in the experiment. For a better accuracy it is recommended to use a large value of $\mathrm{L}$, for instance $200 \mathrm{~cm}$, e. g. by assembling the pendulum at the door frame.

\section{Monitoring strongly magnetic substances}

An extreme response has been observed for highly paramagnetic substances, such as the gadolinium, dysprosium and holmium salts and oxides, as well as for superparamagnetic nanoparticles, e. g. $\mathrm{Fe}_{3} \mathrm{O}_{4}$ (magnetite) or $\gamma-\mathrm{Fe}_{2} \mathrm{O}_{3}$ (maghemite). In such cases the magnet remains attached to the samples, preventing the pendulum oscillation because of their very large attraction. However, the study of such substances can be carried out after their appropriate dilution with diamagnetic substances, such as boric acid, borax or starch, or alternatively, by working with their corresponding solutions.

Because of the dilution effects, the observed pendulum shifts for sample solutions are much smaller than for the pure solids. Therefore, a good compromise is to use relatively concentrated solutions (> $1 \mathrm{~mol} \mathrm{~L}^{-1}$ ). A typical concentration dependence for dysprosium nitrate solutions, obtained with the magnetic pendulum, can be seen in Figure 5.

Magnetic nanoparticles, such as $\mathrm{Fe}_{3} \mathrm{O}_{4}$ exhibit typical superparamagnetic behavior arising from the ferromagnetic coupling of the electron spins under the influence of the magnetic field. ${ }^{16}$ These particles can be conveniently monitored with the pendulum balance using concentrations below $0.5 \%$ by mixing with a diamagnetic substance, like borax or boric acid. Above this value, the pendulum interacting distance will become quite large (e g. $>15 \mathrm{~cm}$ for $\mathrm{L}=150 \mathrm{~cm}$ ) and the behavior will depart from theoretical formalism. At a suitable concentration range, the magnetic susceptibility of the mixture varies linearly with the concentration of $\mathrm{Fe}_{3} \mathrm{O}_{4}$, as shown in Figure 6. Based on the pre-calibration measurements with the $\mathrm{FeSO}_{4} \cdot 7 \mathrm{H}_{2} \mathrm{O}$ standard, the magnetic susceptibility of the such superparamagnetic nanoparticles has been estimated as $6.6 \times 10^{3} \mathrm{~cm}^{3} \mathrm{~mol}^{-1}$, confirming its ferromagnetic nature. ${ }^{4}$

\section{Accessing the pendulum constants}

In addition to the magnetic susceptibility measurements, it is also

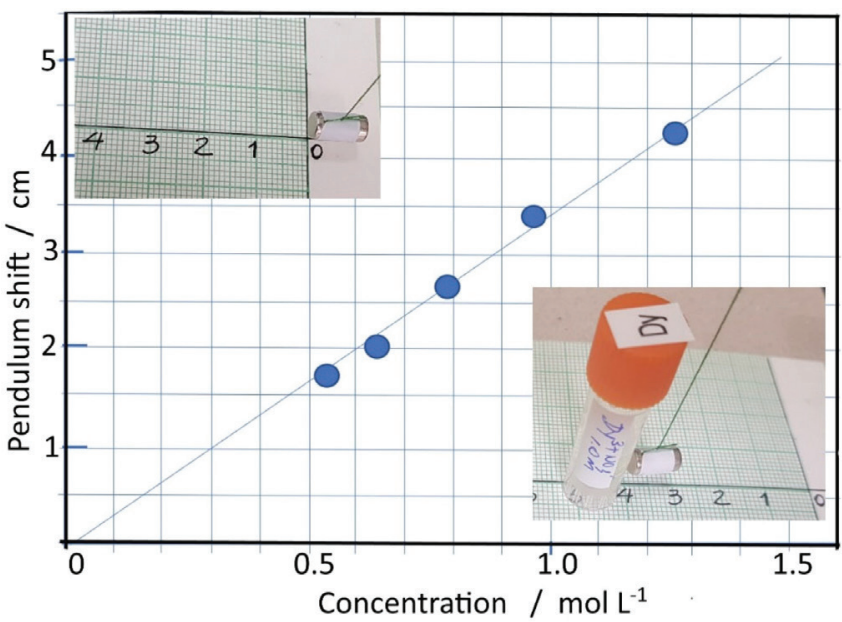

Figure 5. Variation of the pendulum $(L=150 \mathrm{~cm})$ shifts with the concentration of $\mathrm{Dy}^{+}$ions in aqueous solution $\left(25^{\circ} \mathrm{C}\right)$, showing a typical response and the calibration marks in the inset, (the circle sizes represent the errors involved)

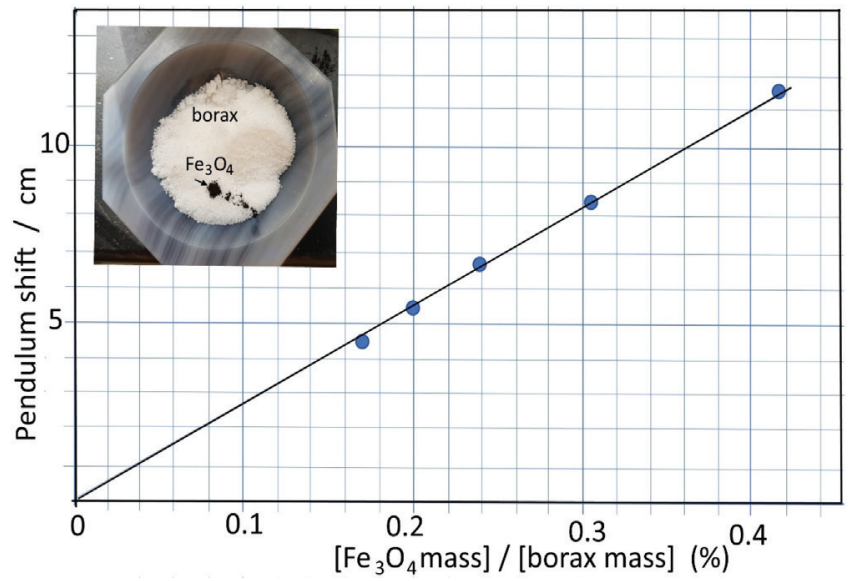

Figure 6. Probing $\mathrm{Fe}_{3} \mathrm{O}_{4}$ superparamagnetic nanoparticles with the pendulum balance $(L=150 \mathrm{~cm})$, after dispersing a minimum amount of the solid $(e . \mathrm{g}$. $10 \mathrm{mg}$ ) into a large excess of borax (5 g), and grinding in an agate mortar, as illustrated in the inset (the circle sizes represent the errors involved)

possible to extract the physical parameters involved in the experiment, such as the pendulum period, $\mathrm{P}$, and the gravity constant, $\mathrm{g}$.

The pendulum period is the time it takes for the oscillating object to complete its cycle, e. g. starting from one extreme, travel to the opposite extreme, and then return to the original location. Theoretically, for small angles oscillation, $\mathrm{P}$ is given by

$$
\mathrm{P}=2 \pi \sqrt{\frac{L}{g}}
$$

The pendulum periods can be precisely measured by recording the number of oscillations during an interval of time, e. g. $30 \mathrm{~s}$, for $\mathrm{L}=75-200 \mathrm{~cm}$, as shown in Table 1 . The observed values were proportional to $\mathrm{L}^{1 / 2}$, as expected theoretically.

From the value of $\mathrm{T}$, the gravity constant $\mathrm{g}$ can be calculated by

$$
\mathrm{g}=\frac{4 \pi^{2}}{T^{2}} L
$$

yielding an average value of $9.81 \mathrm{~m} \mathrm{~s}^{-2}$, in good agreement with the well known gravity acceleration constant. ${ }^{17}$ 


\section{Concluding remarks}

The proposed experiment is suitable for demonstrating the nature of paramagnetic and diamagnetic substances, and for teaching basic principles of physics and chemistry at home, particularly during this covid-19 pandemics. ${ }^{18}$ The balance construction is quite simple and cheap, and the Galileo's pendulum theory can be used to guide the experiments and to calculate the gravity acceleration constant.

For explaining the chemical magnetism, a quantitative approach has been applied by equilibrating the pendulum equations and the magnetic forces. In this way, it has been possible to calculate the magnetic susceptibilities and evaluate the number of unpaired electrons in the metal complex. Since magnetism is related to the electronic structure, further interpretation can be developed, demanding ligand field theory and concepts from interelectronic repulsion and high spin and low spin configurations.

Although one can obtain magnetic susceptibilities of most transition metal elements in this way, the pendulum balance is not particularly suitable for weakly paramagnetic substances, such as copper(II) compounds ( $3 \mathrm{~d}^{9}$ configuration, one unpaired electron), because of the large experimental errors involved. At the other extreme, strongly paramagnetic $\mathrm{Gd}^{3+}, \mathrm{Dy}^{3+}, \mathrm{Ho}^{3+}$ ions, and typical superparamagnetic nanoparticles will interact too strongly with the magnetic probe, and the results depart from the theoretical approximations. In this case, appropriate dilution with diamagnetic substances is necessary in order to use the pendulum balance.

\section{ACKNOWLEDGEMENTS}

The support from Fundação de Amparo à Pesquisa do Estado de São Paulo, FAPESP Temático 2018/21489-1 is gratefully acknowledged.

\section{REFERENCES}

1. Nussenzveig M. H.; Toma, H. E.; Colli, E.; Bagnato, V.S.; Zatz, M.; Dessen, E. M. B.; Barbui, B.; Kits - Aventuras na Ciência, http://www. aventurasnaciencia.ib.usp.br/, accessed August 2020.
2. Nussenzveig, M. H.; Curso de física básica, Edgard Blucher: São Paulo, 2008.

3. van Vleck, J. H.; The theory of electric and magnetic susceptibilities, Oxford University Press: Oxford, 1932.

4. Toma, H. E.; Nanotecnologia molecular - materiais e dispositivos, Edgard Blucher: São Paulo, 2016.

5. Uchiyama, M. K.; Toma, S. H.; Rodrigues, S. F.; Shimada, A. L.; Loiola, R. A.; Cervantes Rodríguez, H. J.; Oliveira, P. V.; Luz, M.; Rabbani, S. R.; Toma, H. E.; Poliselli Farsky, S. H.; Araki, K.; Int. J. Nanomed. 2015, 10, 4731.

6. Melo, F. M.; Almeida, S. N.; Santos, A. D.; Toma, H. E.; NanoWorld J. 2017, 3, 38 .

7. Melo, F. M.; Silveira, A. T.; Quartarolli, L. F.; Kaid, F. F.; Cornejo, D. R.; Toma, H. E.; J. Magn. Magn. Mater. 2019, 487, 165324.

8. Toma, H. E.; Ferreira, A. M. D.; Osorio, V. K. L.; J. Chem. Educ. 1983, 60,600 .

9. MagTek. https://www.magtek.com.br/, accessed August 2020

10. Newton, R. G.; Galileo's pendulum, Harvard University Press: Cambridge, 2004.

11. Museo del Meteorito, San Pedro de Atacama, Chile, http://www. museodelmeteorito.cl, accessed August 2020.

12. CRC Handbook of Chemistry and Physics, CRC Press: Boca Raton, 2013.

13. Mabbs, F. E.; Machin, D. J.; Magnetism and transition metal complexes, Chapman and Hall: London, 1973.

14. Toma, H. E.; Química de coordenação, organometálica e catálise, Edgard Blucher: São Paulo, 2106.

15. Landee, C. P.; Turnbull, M. M.; J. Coord. Chem. 2014, 65, 375.

16. Yamaura, M.; Camilo, R. L.; Sampaio, L. C.; Macedo, M. A.; Nakamura, M.; Toma, H. E.; J. Magn. Magn. Mater. 2004, 279, 210.

17. The international system of units, ISBN 92-822-2213-6, 2006.

18. Levin, M.; The Scientist Magazine, July/August 2020, https://www. the-scientist.com/news-opinion/opinion-use-the-pandemic-to-expandthe-lab-to-the-home-67677?utm_campaign=TS_Dayly News, accessed August 2020. 